\title{
Produção, teor e composição química do óleo essencial de hortelã-japonesa cultivada sob malhas fotoconversoras
}

\author{
Jorge H Chagas'; José Eduardo BP Pinto²; Suzan Kelly V Bertolucci²; Andressa G Costa ${ }^{3}$; Hugo Cesar R \\ de Jesus ${ }^{4}$; Péricles B Alves ${ }^{4}$ \\ ${ }^{1}$ Embrapa Trigo, C. Postal 451, 99001-970 Passo Fundo-RS; jorge.chagas@cnpt.embrapa.br; ${ }^{2}$ UFLA-Depto. Agricultura, C. Postal 3037, \\ 37200-000 Lavras-MG; jeduardo@dag.ufla.br (autor para correspondência); suzan@dag.ufla.br; ${ }^{3} \mathrm{UFG}$, Rod. BR 364, km 192, 75801- \\ 615 Jataí-GO; andressagiovannini@yahoo.com.br; ${ }^{(4)}$ UFS, Depto. Quimica, Av. Marechal Rondon s/n, 49100-000 São Cristovão-SE; \\ pericles@ufs.br
}

\section{RESUMO}

Foi avaliado o efeito da intensidade e da qualidade espectral da luz transmitida pelas malhas fotoconversoras em relação ao crescimento, teor e composição química do óleo essencial das plantas de Mentha arvensis. Foram realizadas duas avaliações, aos 85 dias após o plantio e aos 80 dias após a rebrota das plantas. O delineamento experimental utilizado foi inteiramente casualizado, dispostos em quatro tratamentos e cinco repetições, sendo cada parcela composta de três vasos (uma planta por vaso) em cada corte. Os tratamentos foram caracterizados por plantas de hortelã-japonesa cultivadas a pleno sol e sob malhas com $50 \%$ de sombreamento na cor preta, vermelha ou azul. Foram avaliados a biomassa seca de folhas, caules, parte aérea, raízes e estolões e total, razão raiz/parte aérea, área foliar total, razão de área foliar, área foliar específica, número de brotações, teor, rendimento e composição química do óleo essencial. O crescimento da planta, teor e rendimento de óleo essencial são mais afetados pela intensidade do que pela variação espectral da luz imposta pelas malhas. O sombreamento de $50 \%$ provocado pelas malhas é excessivo, independente da cor. A composição química do óleo essencial não foi afetada consideravelmente pelas malhas.

Palavras-chave: Mentha arvensis, luz, malhas coloridas, sombreamento, mentol.

\begin{abstract}
Production, content and chemical composition of essential oil of mint cultivated under color shading nets

This research was carried out to evaluate the intensive effect and spectral light quality transmitted by the shading nets related to Mentha arvensis plants growth, content and chemical composition. Two evaluations were performed, one 85 days after planting and the other one 80 days after plants reshoot. The experimental design was randomized complete blocks with 4 treatments and 5 replications, each plot with 3 pots (one plant per pot) in each cutting. The treatments consisted of mint cultured under full sun light and under shading net with $50 \%$ of black, red or blue screen. We evaluated the yield of dry leaves biomass, stalks, shoots, roots and stolons and total biomass, root/shoot ratio, total foliar area, foliar area ratio, foliar weight ratio, specific foliar area, shoots number after reshoots, content, yield and chemical composition of essential oil. The plants growth, essential oil content and yield were more affected by light intensity than spectral light quality transmitted by the shading nets. The shading of $50 \%$ by nets is excessive, independently on color. The chemical composition of essential oil was not affected considerably by color shading nets.
\end{abstract}

Keywords: Mentha arvensis, light, colored nets, shading, menthol.

(Recebido para publicação em 8 de maio de 2012; aceito em 18 de março de 2013) (Received on May 8, 2012; accepted on March 18, 2013)

$\mathrm{D}$ entro do gênero Mentha, pertencente à família Lamiaceae, destaca-se a Mentha arvensis, conhecida popularmente como hortelã-japonesa, principalmente pela exploração comercial do óleo essencial extraído de sua parte aérea e também pelo uso medicinal no combate de distúrbios estomacais, do aparelho respiratório e de parasitas intestinais (Chagas et al., 2011a, b). Seu óleo essencial é rico em monoterpenos como o mentol, mentona e outros derivados de valor mercadológico que são amplamente utilizados nas indústrias alimentícias, farmacêuticas, cosméticas, perfumarias e do tabaco (Chagas et al., 2011b).

As plantas podem responder de maneira específica aos estímulos luminosos. Essas respostas não dependem apenas da presença, da atenuação ou da ausência da luz, mas também da qualidade espectral da radiação (Taiz \& Zeiger, 2004). Várias técnicas para manipulação da qualidade da luz têm sido utilizadas. Alguns trabalhos mostram efeitos marcantes sobre a fotomorfogênese de plantas, seja pela iluminação artificial (Pons \& Van Berkel, 2004), por coberturas de solo refletoras, tintas, coberturas ou malhas coloridas para casas de vegetação que modificam a radiação por elas transmitida (Shahak et al., 2004).

As malhas fotoconversoras são capazes de modificar tanto a quantidade como a qualidade da radiação solar transmitida, determinando modificações óticas da dispersão e reflectância da luz. $O$ espectro da malha azul apresenta um pico principal de transmitância na região do azul-verde (400-540 nm), enquanto a malha vermelha possui maior transmitância para comprimentos de ondas superiores a $590 \mathrm{~nm}$ (Oren-Shamir et al., 2001). Segundo Shahak et al. (2004), o fator de diferenciação mais importante entre as malhas é a razão 
azul:vermelho $(\mathrm{A}: \mathrm{V})$, que é maior no ambiente sob a malha azul e menor no ambiente sob a malha vermelha. Já a razão vermelho:vermelho distante (V:VD), principal fator regulatório das reações mediadas pelos fitocromos, é pouco alterada pelas telas coloridas. Neste contexto, o cultivo de plantas utilizando malhas fotoconversoras, de acordo com Oren-Shamir et al. (2001), objetiva combinar a proteção física com a filtragem diferencial da radiação solar, para promover respostas fisiológicas desejáveis melhorando o rendimento dos cultivos.

Alterações sutis no balanço espectral do ambiente podem ser percebidas pelas plantas, produzindo respostas fotomorfogenéticas, gerando ajustes fisiológicos e morfológicos, e que podem atingir o crescimento e o desenvolvimento ( $\mathrm{Li}$ et al., 2000) e a síntese e o acúmulo de óleo essencial, uma vez que estas alterações podem afetar direta ou indiretamente as vias biossintéticas dos metabólitos secundários (Taiz \& Zeiger, 2004).

Diante da grande influência que a radiação solar exerce sobre os vegetais, esta pesquisa foi realizada com o objetivo de avaliar o efeito da intensidade e da qualidade espectral da luz transmitida pelas malhas fotoconversoras (Chromatinet $^{\circledR}$ ) em relação à produção vegetal, aspectos fisiológicos de crescimento, teor, rendimento e composição química do óleo essencial de hortelã-japonesa.

\section{MATERIAL E MÉTODOS}

O experimento foi desenvolvido na Fazenda Gota de Esperança (21 ${ }^{\circ} 14^{\prime} 07^{\prime \prime} \mathrm{S}, 44^{\circ} 58^{\prime} 22^{\prime \prime} \mathrm{O}, 879 \mathrm{~m}$ de altitude), da Universidade Federal de Lavras (UFLA). O município de Lavras está situado na região Sul do estado de Minas Gerais e, de acordo com a classificação climática de Köppen, o clima regional é do tipo Cwa, mas apresenta características de $\mathrm{Cwb}$ com duas estações bem definidas, uma fria e seca, de abril a setembro, e outra quente e chuvosa, de outubro a março (Brasil, 1992).

As exsicatas estão depositadas no Herbário ESAL, do Departamento de Biologia da UFLA e correspondem ao número 3636. As mudas de hortelã-japo- nesa foram produzidas a partir de plantas matrizes utilizando microestacas apicais de cinco centímetros de comprimento e dois milímetros de diâmetro e postas para enraizar em bandejas de poliestireno expandido de 128 células, contendo o substrato comercial Plantmax ${ }^{\circledR}$. Foram cultivadas em casa de vegetação com $70 \%$ de sombreamento utilizando tela sombrite por 35 dias e, posteriormente, aclimatizadas por meio da diminuição gradativa do sombreamento. Os dados climatológicos de temperatura e precipitação da cidade de Lavras, durante o período experimental, foram fornecidos pela Estação Climatológica do Departamento de Engenharia Agrícola da UFLA (a temperatura média e precipitação nos meses de janeiro a junho foram, respectivamente $21,8^{\circ} \mathrm{C}$ e $263,0 \mathrm{~mm} ; 21,8^{\circ} \mathrm{C}$ e $243,3 \mathrm{~mm} ; 21,9^{\circ} \mathrm{C}$ e $194,2 \mathrm{~mm} ; 20,9^{\circ} \mathrm{C}$ e $110,6 \mathrm{~mm} ; 17,8^{\circ} \mathrm{C}$ e $2,8 \mathrm{~mm} ; 17,6^{\circ} \mathrm{C}$ e $14,4 \mathrm{~mm})$.

Em janeiro de 2008, as mudas de 10 $\mathrm{cm}$ de altura foram transplantadas para vasos de $10 \mathrm{~L}$, com substrato homogeneizado, contendo Latossolo Vermelho Distroférrico, areia e esterco bovino curtido na proporção $3: 1: 1$. O solo foi analisado e corrigido com aplicação de calcário 50 dias antes do plantio, conforme Comissão de Fertilidade do Solo do Estado de Minas Gerais (1999). Foi realizada também a análise do substrato, cujos resultados foram: classe textural média; $\mathrm{pH}=6,0 ; \mathrm{P}=47,1 \mathrm{mg} \mathrm{dm}^{-3} ; \mathrm{K}=$ $381 \mathrm{mg} \mathrm{dm}^{-3} ; \mathrm{Ca}=4,2 \mathrm{cmol}_{\mathrm{c}} \mathrm{dm}^{-3} ; \mathrm{Mg}=$ $1,5 \mathrm{cmol}_{\mathrm{c}} \mathrm{dm}^{-3} ; \mathrm{Al}=0,0 \mathrm{cmol}_{\mathrm{c}} \mathrm{dm}^{-3}$; $\mathrm{H}+\mathrm{Al}=1,9 \mathrm{cmol} \mathrm{dm}^{-3}$; matéria orgânica $=1,5 \mathrm{dag} \mathrm{kg}^{-1} \mathrm{e}$ índice de saturação de bases $(\mathrm{V})=77,8 \%$.

Os tratamentos foram caracterizados pelo cultivo das plantas sob disponibilidade de radiação solar incidente e qualidade espectral: pleno sol e malhas com $50 \%$ de sombreamento na cor preta, Chromatinet ${ }^{\circledR}$ azul e Chromatinet ${ }^{\circledR}$ vermelha, fornecidas pela empresa Polysack Plastic Industries ${ }^{\circledR}$. Os vasos foram distribuídos entre quatro tratamentos, cada um composto de 30 vasos, divididos em duas avaliações: 15 vasos avaliados aos 85 dias após o transplantio das mudas e 15 vasos foram avaliados 80 dias pós-rebrota. Os vasos foram dispostos em delineamento inteiramente casualizado com cinco repetições, cada uma composta de três vasos (1 planta/ vaso).

No final do mês de março, aos 85 dias após o transplantio das mudas para os vasos, foi realizado o primeiro corte, rente ao solo, de todas as plantas nos 30 vasos de cada tratamento, onde 15 vasos foram avaliados e os outros 15 vasos permaneceram com sistema radicular para avaliação da rebrota das plantas. Após o primeiro corte, os vasos remanescentes receberam uma adubação em cobertura com esterco bovino curtido de $100 \mathrm{~g} \mathrm{vaso}^{-1}$. Aos 80 dias após o primeiro corte, foi realizado o segundo corte no final do mês de junho. O manejo e tratos culturais foram realizados uniformemente entre os tratamentos. A irrigação foi realizada através de regadores manuais, vaso por vaso, até o solo atingir a capacidade de campo, três vezes por semana.

Ao final do primeiro e do segundo corte das plantas de hortelã-japonesa as folhas foram destacadas dos ramos e realizada a detecção da área foliar total $\left(\mathrm{AFT}, \mathrm{dm}^{2}\right)$ de cinco plantas de cada tratamento (1 planta/repetição), em 100\% das folhas, por meio de um integralizador de área foliar Model LI-3100, Área Meter marca Licor. Posteriormente, as partes aéreas das duas plantas restantes de cada uma das parcelas também foram separadas em folhas e caules, acondicionadas em sacos de papel Kraft e colocadas em estufa de circulação forçada de ar, a $37 \pm 1^{\circ} \mathrm{C}$. As raízes foram lavadas e, depois de retirada a umidade excessiva, também foram conduzidas à estufa em sacos de papel Kraft, até atingirem peso constante. Após a detecção da área foliar e do processo de secagem, foram obtidas as biomassas secas de todas as plantas (3 plantas/repetição) e avaliadas as características de crescimento: biomassa seca de folhas (BSF, g planta $\left.{ }^{-1}\right)$, caules (BSC, g planta ${ }^{-1}$ ), parte aérea (BSPA, g planta $^{-1}$ ), raízes e estolões (BSR, $g$ planta $^{-1}$ ), biomassa seca total (BST, g parcela $^{-1}$ ), razão raiz/parte aérea (BSR/ BSPA, $\left.g^{-1}\right)$. A partir dos valores de área foliar total (AFT), da biomassa seca total (bst) e da biomassa seca das folhas (bsf) de cada planta usada na detecção da área foliar, foram determinadas a razão da área foliar $\left(\mathrm{RAF}=\mathrm{AFT} / \mathrm{bst}, \mathrm{dm}^{2} \mathrm{~g}^{-1}\right)$ e a área foliar específica $(\mathrm{AFE}=\mathrm{AFT} / \mathrm{bsf}$, 
$\mathrm{dm}^{2} \mathrm{~g}^{-1}$ ) (adaptado de Benincasa, 2004).

Entre o primeiro e o segundo corte, também foram realizadas avaliações referentes ao número de brotações em cada tratamento. Aos 20 e aos 40 dias após o primeiro corte das plantas, foram realizadas contagens das brotações maiores que um centímetro, nos 15 vasos que permaneceram para serem avaliados no segundo corte das plantas de hortelã-japonesa, sendo cinco repetições com três vasos cada.

A extração de óleo essencial, nas folhas correspondentes a ambos os cortes das plantas, foi realizado pelo método de hidrodestilação em aparelho modificado de Clevenger. Sessenta gramas de folhas secas, após serem pulverizadas em moinho de facas, foram imediatamente transferidas para um balão volumétrico de 2 L e acrescentado um volume de 1,2 L de água destilada. Após a detecção de inicio de fervura, começou-se a cronometrar. Findo o período de extração de uma hora, o hidrolato, foi submetido à partição líquido-líquido em funil de separação, com três porções de $25 \mathrm{~mL}$ de diclorometano (cada porção descansou por 20 minutos). As frações orgânicas de cada repetição foram reunidas e secas com uma porção de cerca de 3 $\mathrm{g}$ de sulfato de magnésio anidro. $\mathrm{O}$ sal foi removido por filtração simples, e o solvente evaporado, à temperatura ambiente, sob capela de exaustão de gases até atingir peso constante, obtendo-se, então, o óleo essencial purificado. Em seguida, as massas dos óleos essenciais foram determinadas em balança digital, com sensibilidade $0,0001 \mathrm{~g}$ e calculados seus teores percentuais do óleo essencial nas folhas $(\mathrm{TOE} \%=$ massa do óleo $(\mathrm{g}) / 60 \mathrm{~g}$ x 100 . O rendimento foi calculado pela fórmula $\mathrm{ROE}=$ biomassa seca das folhas/planta $(\mathrm{g}) \times$ massa do óleo obtido $(\mathrm{g}) / 60 \mathrm{~g}$. O delineamento utilizado foi inteiramente casualizado, com cinco repetições.

As análises de composição química foram realizadas empregando-se uma amostra composta compreendida da reunião de alíquotas equivolumétricas do óleo volátil das cinco repetições de cada tratamento. As análises foram realizadas em laboratório da Universidade Federal de Sergipe. Foi empregado um sistema de cromatografia em fase gasosa, acoplado a um espectrômetro quadrupolar de massas (GC-EM) Shimadzu ${ }^{\circledR}$ QP5050A (Quioto, Japão), nas seguintes condições operacionais: coluna capilar de sílica fundida, modelo CBP-5 (30 m comprimento x $0,25 \mathrm{~mm}$ diâmetro interno $\mathrm{x} 0,25 \mu \mathrm{m}$ de espessura do filme em 5\% de fenilmetilpolisiloxano) (Shimadzu ${ }^{\circledR}$, Japão), hélio como gás

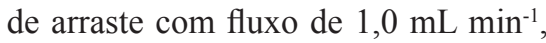
aquecimento com temperatura programada $\left(60^{\circ} \mathrm{C}\right.$ com rampa de temperatura de $3^{\circ} \mathrm{C} \mathrm{min}^{-1}$ até $240^{\circ} \mathrm{C}$ e, em seguida, de $10^{\circ} \mathrm{C} \mathrm{min}^{-1}$ até $270^{\circ} \mathrm{C}$, mantendo-se uma isoterma de 5 minutos). A energia de ionização do detector foi de $70 \mathrm{eV}$, sendo o volume de injeção da amostra de $0,2 \mu \mathrm{L}\left(20 \% \mathrm{em} \mathrm{CH}_{2} \mathrm{Cl}_{2}\right.$, grau ultrarresíduo, Baker, EUA) e razão de injeção de 1:20. As temperaturas do injetor e do detector foram mantidas em $220^{\circ} \mathrm{C}$ e $240^{\circ} \mathrm{C}$, respectivamente. A análise foi conduzida no modo varredura, à velocidade de 1,0 scan s$^{-1}$, com intervalo de aquisição de massas de 40-400 $\mathrm{m} \mathrm{z}^{-1}$. A análise quantitativa foi obtida pela integração do cromatograma total de íons (TIC). A identificação dos constituintes foi realizada por comparação dos espectros de massas com o banco de dados das bibliotecas NIST/EPA/NHI (1998), por comparação dos espectros de massas e índices de retenção (IR) com os da literatura (Adams, 2001) e coinjeção com padrões autênticos. Os IR foram determinados por meio da coinjeção com uma mistura de hidrocarbonetos, $\mathrm{C}_{8}-\mathrm{C}_{32}$ (Sigma, EUA) e calculados empregando-se a equação de Van Den Dool \& Kratz (1963).

A análise estatística dos dados obtidos foi realizada pelo programa SISVAR $^{\circledR}$, versão 4.3 (Ferreira, 2003). As médias dos tratamentos foram submetidas à análise de variância pelos testes de F e de Tukey $(\mathrm{p}<0,05)$.

\section{RESULTADOS E DISCUSSÃO}

O acúmulo de biomassa seca nos diferentes órgãos das plantas foi afetado pelo uso das malhas coloridas, como também pela intensidade, quando comparadas às plantas cultivadas a pleno sol, tanto no primeiro corte após o transplantio como no segundo (Tabelas $1 \mathrm{e}$ 2 , respectivamente). Observou-se maior sensibilidade das plantas de hortelã-japonesa à intensidade de luz para a produção de biomassa, de forma que o sombreamento empregado pelas malhas de $50 \%$ foi excessivo para a espécie, independente da cor, não resultando em benefícios em relação às plantas cultivadas a pleno sol, exceto para o acúmulo de biomassa seca dos caules (BSC), que não diferiu, estatisticamente, em relação às malhas preta e vermelha tanto no primeiro como no segundo corte (Tabelas 1 e 2).

$\mathrm{O}$ acúmulo de biomassa seca pelas raízes e a razão raiz/parte aérea também foram maiores nas plantas cultivadas a pleno sol, indicando uma alocação preferencial de biomassa seca para o sistema radicular (Tabelas 1 e 2). Essa alocação de biomassa seca para as raízes evidencia-se, preferencialmente, em função da intensidade luminosa. $\mathrm{O}$ maior investimento de fotoassimilados em raízes, em detrimento de folhas nestas plantas, é condizente com a estratégia adaptativa de aumentar a capacidade de absorção de água e nutrientes e de sobreviver em ambientes com maior incidência de ventos e alta irradiância $e$, consequentemente, maior exigência hídrica.

Resultados semelhantes da distribuição e acúmulo de biomassa pelos diferentes órgãos das plantas de hortelã-japones foram verificados em alguns trabalhos (Melo \& Alvarenga, 2009; Oliveira et al., 2009; Costa et al., 2010). Contudo, Martins et al. (2008) verificaram que o acúmulo de biomassa seca de folhas e caules de Ocimum gratissimum foi semelhante sob cultivo protegido em malhas coloridas e pleno sol, porém, o acúmulo de biomassa das raízes variou entre as malhas, indicando que as respostas quanto à intensidade luminosa $\mathrm{e}$ ao emprego das malhas coloridas são particulares para cada espécie. Brant et al. (2009), trabalhando com Melissa officinallis e Souza et al. (2011) com guaco, verificaram que as plantas cultivadas sob malhas coloridas acumularam maior biomassa seca do que em pleno sol.

Entre as malhas coloridas, no primeiro corte, a maior diferença foi no acúmulo de biomassa seca das raízes que, consequentemente, colaborou para 
Tabela 1. Biomassa seca das folhas (BSF), dos caules (BSC), da parte aérea (BSPA), das raízes e estolões (BSR), total (BST), relação raiz/ parte aérea (BSR/BSPA), área foliar total (AFT), área foliar específica (AFE), razão da área foliar (RAF), teor (TOE) e rendimento de óleo essencial (ROE) de Mentha arvensis cultivada a pleno sol e sombreamento (50\%) com malhas preta, vermelha e azul, avaliadas 85 dias após o transplantio, primeiro corte ${ }^{1}$ (leaves biomass, stalks, shoots, roots and stolon, total biomass, ratio root/shoot, total foliar área, specific foliar área, ratio of foliar área, content and yield of essential oil of Mentha arvensis cultured in full sunlight and shading (50\%) with black, red and blue nets, evaluated at 85 days after planting, the first cutting). Lavras, UFLA, 2008.

\begin{tabular}{lccccrr}
\hline \multirow{2}{*}{ Parâmetros } & \multicolumn{7}{c}{ Primeiro corte } \\
\cline { 2 - 7 } & Pleno sol & Malha preta & Malha vermelha & Malha azul & Média geral & CV (\%) \\
\hline BSF (g/planta) & $13,50 \mathrm{a}$ & $8,59 \mathrm{~b}$ & $8,70 \mathrm{~b}$ & $7,37 \mathrm{~b}$ & 9,54 & 15,68 \\
BSC (g/planta) & $16,02 \mathrm{a}$ & $14,77 \mathrm{ab}$ & $14,23 \mathrm{ab}$ & $12,70 \mathrm{~b}$ & 14,43 & 8,58 \\
BSPA (g/planta) & $29,53 \mathrm{a}$ & $23,36 \mathrm{~b}$ & $22,94 \mathrm{~b}$ & $20,07 \mathrm{~b}$ & 23,97 & 10,06 \\
BSR (g/planta) & $43,81 \mathrm{a}$ & $30,98 \mathrm{~b}$ & $25,54 \mathrm{bc}$ & $22,85 \mathrm{c}$ & 30,79 & 13,01 \\
BST (g/planta) & $73,33 \mathrm{a}$ & $54,34 \mathrm{~b}$ & $48,47 \mathrm{bc}$ & $42,92 \mathrm{c}$ & 54,76 & 10,90 \\
BSR/BSPA (g/g) & $1,48 \mathrm{a}$ & $1,32 \mathrm{~b}$ & $1,11 \mathrm{c}$ & $1,13 \mathrm{c}$ & 1,25 & 6,42 \\
AFT (dm $/$ planta) & $18,95 \mathrm{~b}$ & $27,94 \mathrm{a}$ & $25,78 \mathrm{a}$ & $23,06 \mathrm{ab}$ & 23,93 & 12,68 \\
AFE (dm $/ \mathrm{g})$ & $1,72 \mathrm{~b}$ & $3,05 \mathrm{a}$ & $3,43 \mathrm{a}$ & $3,35 \mathrm{a}$ & 2,88 & 12,66 \\
RAF (dm $/ \mathrm{g})$ & $0,27 \mathrm{~b}$ & $0,50 \mathrm{a}$ & $0,55 \mathrm{a}$ & $0,54 \mathrm{a}$ & 0,46 & 11,53 \\
TOE (peso \%) & $3,22 \mathrm{a}$ & $2,52 \mathrm{~b}$ & $2,20 \mathrm{~b}$ & $2,25 \mathrm{~b}$ & 2,54 & 12,74 \\
ROE (g/planta) & $0,95 \mathrm{a}$ & $0,57 \mathrm{~b}$ & $0,50 \mathrm{~b}$ & $0,45 \mathrm{~b}$ & 0,61 & 15,99 \\
\hline
\end{tabular}

${ }^{1}$ Médias seguidas de mesma letra na linha não diferem significativamente entre si pelo teste de Tukey, a 5\% de probabilidade (means followed by same letters in the line do not differ significantly, Tukey, $5 \%$ ).

Tabela 2. Biomassa seca das folhas (BSF), dos caules (BSC), da parte aérea (BSPA), das raízes e estolões (BSR), total (BST), relação raiz/ parte aérea (BSR/BSPA), área foliar total (AFT), área foliar específica (AFE), razão da área foliar (RAF), teor (TOE) e rendimento de óleo essencial (ROE) de Mentha arvensis cultivada a pleno sol e sombreamento (50\%) com malhas preta, vermelha e azul, avaliadas 80 dias após o primeiro corte, o segundo corte ${ }^{1}$ (leaves biomass, stalks, shoots, roots and stolon, total biomass, ratio root/shoot, total foliar area, specific foliar area, ratio foliar area, content and yield of essential oil of Mentha arvensis cultivated in full sunlight and shading (50\%) with black, red and blue nets, evaluated 80 days after the first cutting, the second cutting). Lavras, UFLA, 2008.

\begin{tabular}{lrccrrr}
\hline \multirow{2}{*}{ Parâmetros } & \multicolumn{7}{c}{ Segundo corte } \\
\cline { 2 - 7 } & Pleno sol & Malha preta & Malha vermelha & Malha azul & Média geral & CV (\%) \\
\hline BSF (g/planta) & $13,69 \mathrm{a}$ & $9,72 \mathrm{~b}$ & $7,05 \mathrm{~b}$ & $7,22 \mathrm{~b}$ & 9,42 & 15,99 \\
BSC (g/planta) & $15,29 \mathrm{a}$ & $14,09 \mathrm{ab}$ & $11,80 \mathrm{ab}$ & $11,27 \mathrm{~b}$ & 13,11 & 14,74 \\
BSPA (g/planta) & $28,98 \mathrm{a}$ & $23,81 \mathrm{~b}$ & $18,85 \mathrm{c}$ & $18,49 \mathrm{c}$ & 22,53 & 14,36 \\
BSR (g/planta) & $56,98 \mathrm{a}$ & $40,26 \mathrm{~b}$ & $27,94 \mathrm{c}$ & $29,54 \mathrm{c}$ & 38,68 & 13,06 \\
BST (g/planta) & $85,97 \mathrm{a}$ & $64,07 \mathrm{~b}$ & $46,79 \mathrm{c}$ & $48,03 \mathrm{c}$ & 61,21 & 13,54 \\
BSR/BSPA (g/g) & $1,96 \mathrm{a}$ & $1,69 \mathrm{~b}$ & $1,48 \mathrm{~b}$ & $1,59 \mathrm{~b}$ & 1,68 & 8,45 \\
AFT (dm²/planta) & $17,71 \mathrm{~b}$ & $25,43 \mathrm{a}$ & $23,73 \mathrm{a}$ & $23,22 \mathrm{a}$ & 22,52 & 9,65 \\
AFE (dm $/ \mathrm{g})$ & $1,62 \mathrm{c}$ & $2,43 \mathrm{~b}$ & $3,47 \mathrm{a}$ & $3,32 \mathrm{a}$ & 2,71 & 4,81 \\
AFE (dm $/ \mathrm{g})$ & $0,20 \mathrm{c}$ & $0,39 \mathrm{~b}$ & $0,53 \mathrm{a}$ & $0,48 \mathrm{a}$ & 0,40 & 11,79 \\
RAF (dm 2 /g) & $3,43 \mathrm{a}$ & $2,92 \mathrm{~b}$ & $2,68 \mathrm{~b}$ & $2,63 \mathrm{~b}$ & 2,91 & 10,02 \\
TOE (peso \%) & $0,98 \mathrm{a}$ & $0,68 \mathrm{~b}$ & $0,49 \mathrm{bc}$ & $0,48 \mathrm{c}$ & 0,65 & 16,44 \\
\hline
\end{tabular}

${ }^{1}$ Médias seguidas de mesma letra na linha não diferem significativamente entre si pelo teste de Tukey, a $5 \%$ de probabilidade (means followed by same letters in the line do not differ significantly, Tukey, 5\%).

o maior acúmulo de biomassa seca total nas plantas cultivadas sob malha preta em relação às plantas cultivadas sob malha azul (Tabela 1). No segundo corte, o acúmulo da biomassa seca das raízes, da parte aérea e da biomassa seca total das plantas cultivadas sob malha preta em relação às malhas vermelha e azul foi estatisticamente superior (Tabela 2). Isso provavelmente ocorreu devido ao maior acúmulo de BSR observado no primeiro corte, já que a maior parte das brotações surge dos estolões o que, consequentemente, pode ter contribuído para o crescimento rápido e intenso das plantas e os maiores acúmulos de biomassas.

A área foliar total (AFT) foi maior nas plantas cultivadas sob as malhas preta e vermelha em relação às cultivadas a pleno sol, contudo, não se diferenciando estatisticamente do cultivo sob malha azul, no primeiro corte (Tabela 1). No segundo corte, as plantas cultivadas sob 
Tabela 3. Número de brotações totais de Mentha arvensis cultivada a pleno sol e sombreamento (50\%) com malhas preta, vermelha e azul, avaliadas aos 20 e aos 40 dias após o primeiro corte ${ }^{1}$ (total shoot number of Mentha arvensis cultured at full sunlight and shading (50\%) with black, red and blue nets, evaluated at 20 and 40 days after first cutting). Lavras, UFLA, 2008.

\begin{tabular}{lcccccc}
\hline Avaliações & Pleno sol & Malha preta & Malha vermelha & Malha azul & Média geral & CV (\%) \\
\hline 20 dias & $9,93 \mathrm{a}$ & $5,60 \mathrm{~b}$ & $4,46 \mathrm{~b}$ & $4,00 \mathrm{~b}$ & 5,99 & 21,26 \\
40 dias & $28,06 \mathrm{a}$ & $21,86 \mathrm{a}$ & $11,46 \mathrm{~b}$ & $12,26 \mathrm{~b}$ & 18,41 & 20,01 \\
\hline
\end{tabular}

${ }^{1}$ Médias seguidas de mesma letra na linha não diferem significativamente entre si pelo teste de Tukey, a $5 \%$ de probabilidade (means followed by same letters in the line do not differ significantly, Tukey, $5 \%$ ).

Tabela 4. Composição química do óleo essencial de Mentha arvensis cultivada sob pleno sol (PS) e sob sombreamento (50\%) com malhas preta (MP), vermelha (MV) e azul (MA), no primeiro e segundo cortes (essential oil chemical composition of Mentha arvensis cultured under full sunlight and shading (50\%) with black, red and blue nets, at first and second cutting). Lavras, UFLA, 2008.

\begin{tabular}{|c|c|c|c|c|c|c|c|c|c|}
\hline \multirow{2}{*}{$I^{*} *$} & \multirow{2}{*}{ Constituinte } & \multicolumn{4}{|c|}{ Primeiro corte } & \multicolumn{4}{|c|}{ Segundo corte } \\
\hline & & PS & MP & MV & MA & PS & MP & MV & $\overline{\text { MA }}$ \\
\hline$\overline{1029}$ & Limoneno & 0,30 & $\mathrm{n}$ & $\mathrm{n}$ & $\mathrm{n}$ & $\mathrm{n}$ & $\mathrm{n}$ & $\mathrm{n}$ & $\mathrm{n}$ \\
\hline 1096 & Linalol & 0,48 & 0.63 & 0,60 & 0,48 & 0,50 & $\mathrm{n}$ & $\mathrm{n}$ & $\mathrm{n}$ \\
\hline 1152 & Mentona & 2,48 & 2,28 & 2,11 & 1,56 & 0,63 & 1,11 & 0,83 & 0,63 \\
\hline 1162 & iso-mentona & 1,43 & 1,39 & 1,40 & 1,11 & 0,94 & 1,09 & 0,90 & 0,75 \\
\hline 1165 & neo-mentol & 1,87 & 1,83 & 1,92 & 1,69 & 2,02 & 1,76 & 2,01 & 1,75 \\
\hline 1171 & Mentol & 90,29 & 90,63 & 92,69 & 92,68 & 93,71 & 92,96 & 93,87 & 95,08 \\
\hline 1182 & iso-mentol & 0,17 & 0,15 & $\mathrm{n}$ & $\mathrm{n}$ & 0,28 & $\mathrm{n}$ & $\mathrm{n}$ & $\mathrm{n}$ \\
\hline 1188 & $\alpha$-terpineol & 0,23 & 0,22 & $\mathrm{n}$ & 0,21 & $\mathrm{n}$ & $\mathrm{n}$ & $\mathrm{n}$ & $\mathrm{n}$ \\
\hline 1235 & $\begin{array}{l}\text { 3-metil-butanoato de } \\
\text { 3Z-hexenila }\end{array}$ & 0,18 & 0,21 & $\mathrm{n}$ & $\mathrm{n}$ & $\mathrm{n}$ & $\mathrm{n}$ & $\mathrm{n}$ & $\mathrm{n}$ \\
\hline 1252 & Piperitona & 0,56 & 0,63 & 0,60 & 0,60 & 0,46 & 0,65 & 0,66 & 0,61 \\
\hline 1419 & $\beta$-cariofileno & 0,78 & 0,65 & 0,66 & 0,61 & 0,66 & 0,85 & 0,69 & 0,64 \\
\hline 1485 & Germacreno D & $\mathrm{n}$ & 0,34 & $\mathrm{n}$ & 0,33 & $\mathrm{n}$ & 0,74 & 0,45 & 0,53 \\
\hline$\overline{\text { Total }}$ & & 98,77 & 99,30 & 99,98 & 99,27 & 99,20 & 99,16 & 99,41 & 99,99 \\
\hline
\end{tabular}

*Índice de retenção relativo à série de $n$-alcanos $\left(\mathrm{C}_{8}-\mathrm{C}_{32}\right)$ em coluna CBP-5 (coefficient of retention relative to the series of $n$-alkanes $\left(\mathrm{C}_{8}-\mathrm{C}_{32}\right)$ in CBP-5 column). n: não detectados (not detected).

as malhas coloridas tiveram maiores AFT em relação às cultivadas a pleno sol (Tabela 2). Para área foliar específica (AFE) e razão da área foliar (RAF), os maiores valores foram registrados nas plantas cultivadas sob as malhas coloridas no primeiro corte (Tabela 1). Já no segundo corte, o cultivo sob as malhas vermelha e azul apresentaram maiores índices, seguidos pela malha preta (Tabela 2).

Os resultados das análises foliares, em plantas de hortelã-japonesa cultivadas sob as malhas $(50 \%$ de sombreamento), também demonstram ser mais influenciados pela intensidade do que pela qualidade espectral da luz. Essa influência da intensidade luminosa sobre as características foliares e de crescimento, revela a plasticidade fenotípica que esta espécie possui, quando cultivada em ambientes com diferentes luminosidades. Segundo Benincasa (2004), as maiores AFT, AFE e RAF indicam maior superfície fotossintética, menor espessamento foliar e maior proporção de tecido fotossinteticamente ativo na forma de área foliar respectivamente. Essa estratégia da planta em aumentar a superfície fotossintética, de acordo com Jones \& Mcleod (1990), visa garantir um aproveitamento mais eficiente das reduzidas intensidades luminosas sob sombreamento e, consequentemente, compensar as baixas taxas fotossintéticas por unidade de área foliar, característica de uma folha de sombra. Já Taiz \& Zeiger, (2004) afirmam que plantas cultivadas sob sombreamento desenvolvem limbos foliares com menor espessura em relação às plantas cultivadas a pleno sol e que isso pode também ser entendido como mecanismo de proteção da planta contra as altas irradiações. Essa influência da intensidade luminosa nos mecanismos de adaptabilidade de outras espécies é encontrada em alguns trabalhos, sob condições experimentais semelhantes (Martins et al., 2008; Melo \& Alvarenga, 2009; Oliveira et al., 2009; Brant et al., 2010; Souza et al., 2011).

Comparando-se a variação entre as malhas, a AFT não apresentou diferenças estatísticas nos dois cortes. Oliveira et al. (2009), em estudos com Artemisia vulgaris, observaram que a área foliar nas plantas sob a malha azul foi menor em relação às malhas preta e vermelha. Já Kasperbauer (1994) relatou que sob luz vermelha, algumas espécies de plantas podem diferenciar-se pela expansão do limbo foliar para obter maior van- 
tagem competitiva, o que também não foi observado nesta espécie em estudo.

Quanto ao número de brotações mensuradas aos 20 e aos 40 dias após o primeiro corte, foram maiores nos vasos com plantas que tiveram seu cultivo a pleno sol, não se diferenciando apenas das brotações sob a malha preta aos 40 dias (Tabela3). Esse maior número de brotos a pleno sol e nos cultivos sob malha preta aos 40 dias, pode ser explicado pelo maior acúmulo de raízes e estolões observados na primeira avaliação (Tabela 1). Segundo Chagas et al. (2008), a produção de estolões pode influenciar a rebrota e produção de biomassa seca da parte aérea das plantas de hortelã-japonesa nos cortes seguintes.

As plantas cultivadas a pleno sol apresentaram maior teor e rendimento de óleo essencial, tanto no primeiro quanto no segundo corte das plantas (Tabelas 1 e 2). Entre as malhas, apenas a preta no segundo corte apresentou maiores rendimentos de óleo essencial diferenciando-se da malha azul. Esses maiores teores de óleo essencial em condições de pleno sol podem estar associados a uma estratégia adaptativa a esse ambiente, por ele apresentar maiores taxas de evapotranspiração, com maior incidência de ventos e irradiância e, consequentemente, maior exigência hídrica e de outros agentes ambientais. Conforme Mattos \& Innecco (2002), o óleo essencial é proveniente do metabolismo secundário e é bastante influenciado por fatores ambientais. Ming (1998) concorda que, em condições estressantes, há uma maior produção de óleo essencial, o que poderia explicar também uma ligeira elevação nos teores de óleo essencial do primeiro corte, realizado no final do mês de março, para o segundo corte, realizado no final do mês de junho, quando as plantas da rebrota cresceram sob condições de baixa precipitação e, principalmente, de temperaturas baixas. Souza (2007), em estudos de intensidade luminosa com Lippia sidoides obteve resultados semelhantes, onde os cultivos a pleno sol tiveram maior teor e rendimento de óleo essencial. Outros autores, em experimentos com outras espécies, encontraram respostas distintas. Sales et al. (2009) observaram que para a espécie Hyptis marrubioides o teor de óleo essencial mostrou-se insensível aos níveis de irradiância. Já Martins et al. (2008) observaram que o teor de óleo essencial de Ocimum gratissimum foi influenciado pela qualidade de luz e que o cultivo sob o telado azul foi superior ao dos demais. Esses resultados indicam que cada espécie pode responder de maneira distinta aos estímulos ambientais em relação à produção de óleo essencial.

Independente dos ambientes de cultivo testados ou da época de corte, as plantas de hortelã-japonesa apresentaram teores acima de 90,29\% de mentol e em média foram identificados cerca de $99,4 \%$ dos constituintes totais (Tabela 4). Os teores de mentol tiveram acréscimos de $1,18 \%$ a 3,42\% entre o primeiro e o segundo cortes quando os ambientes foram comparados entre si. O cultivo sob malhas nos dois cortes, não incrementaram, expressivamente, o teor médio de mentol que foi de 92,98\% em relação a 92,00\% no pleno sol.

Fazendo a mesma comparação, a mentona teve uma queda do primeiro para o segundo corte de $0,93 \%$ a $1,85 \%$, o que pode explicar, ao menos em parte, a elevação dos teores de mentol no segundo corte. A biossíntese do mentol envolve diversas etapas a partir da via plastídica do ácido mevalônico que leva à formação dos isômeros isoprenóides, isopentenil pirofosfato (IPP) e dimetilalil pirofosfato (DMAPP), tendo como última etapa da via a redução enzimática da mentona a mentol (Croteau et al., 2005).

Os resultados das análises químicas do óleo essencial de hortelã-japonesa também demonstraram algumas diferenças na qualidade e na quantidade dos constituintes em resposta à manipulação espectral. No segundo corte, as malhas não produziram alguns constituintes químicos que foram produzidos no óleo essencial das folhas do primeiro corte, tais como o linalol, o $\alpha$-terpineol e o 3-metil-butanoato de 3Z-hexenila (Tabela 4). Com exceção da malha vermelha, o número de constituintes detectados no primeiro corte reduziu em relação ao segundo, sendo que a maior redução ocorreu nas plantas cultivadas sob a malha preta. Na malha preta, os constituintes linalol, iso-mentol, $\alpha$-terpineol e 3-metil-butanoato de 3Z-hexenila que estavam presentes no primeiro corte não foram detectados no segundo. Na malha vermelha, apesar do número de constituintes ter sido o mesmo, a composição química do primeiro e do segundo corte foi diferente, com a presença de linalol $(0,60 \%)$ e ausência de germacreno D no primeiro corte e ausência de linalol e presença de germacreno D $(0,45 \%)$ no segundo corte. Independente do primeiro ou do segundo cortes, o germacreno D não foi identificado nas plantas cultivadas sob sol pleno.

Apesar do óleo essencial de hortelã-japonesa não ter apresentado diferenças qualitativas e quantitativas pronunciadas entre os ambientes e os cortes, as pequenas diferenças observadas demonstraram que é possível alterar as vias biossintéticas e o teor dos constituintes químicos pela manipulação espectral ou rebrota. Corrêa (2008), em pesquisas com Origanum vulgare, também observou menor número de compostos identificados nas plantas cultivadas sob as malhas vermelha e azul. Em Thymus vulgaris, o número de constituintes identificados foi maior nas plantas cultivadas sob $100 \%$ de luminosidade (Li et al., 1996). Brant et al. (2009) quantificaram maior teor de citral em Melissa officinalis cultivada sob malha vermelha.

Conclui-se que o crescimento das plantas, o teor e o rendimento de óleo essencial são mais afetados pela intensidade do que pela variação espectral da luz imposta pelas malhas. O sombreamento de $50 \%$ proporcionado pelas malhas não traz ganhos de produtividade para hortelã-japonesa.

\section{AGRADECIMENTOS}

À Coordenação de Aperfeiçoamento de Nível Superior (CAPES), pela concessão da bolsa de estudos, ao Conselho Nacional de Desenvolvimento Científico $(\mathrm{CNPq})$ e à Fundação de Amparo à Pesquisa do Estado de Minas Gerais (FAPEMIG), pelo apoio financeiro, pela bolsa de produtividade e apoio técnico.

\section{REFERÊNCIAS}

ADAMS RP. 2001. Identification of essential 
oil components by gas chromatography/ quadrupole mass sprestroscopy. Allured: Illinois. $421 \mathrm{p}$.

BENICASA MMP. 2004. Análise de crescimento de plantas: noções básicas. Jaboticabal: FUNEP, 42 p.

BRANT RS; PINTO JEBP; ROSAL LF; ALBUQUERQUE CJB; FERRIPH; CORRÊA RM. 2009. Crescimento, teor e composição do óleo essencial de melissa cultivada sob malhas fotoconversoras. Ciência Rural 39: 1401-1407.

BRANT RS; PINTO JEBP; ROSAL LF; CASTRO EM; OLIVEIRA C; ALBUQUERQUE CJB. 2010. Características fisiológicas e anatômicas de Melissa officinallis L. (Lamiaceae) cultivadas sob diferentes condições de luminosidade. Magistra 22: 146-152.

BRASIL. Ministério da Agricultura e Reforma Agrária. 1992. Normas climatológicas de 1961-1990. Brasília: Ministério da Agricultura e Reforma Agrária, 84 p.

CHAGAS JH; PINTO JEBP; BERTOLUCCI SKV; NALON FH. 2008. Produção de mudas de hortelã-japonesa em função da idade e de diferentes tipos de estaca. Ciência Rural 38: 2157-2163.

CHAGAS JH; PINTO JEBP; BERTOLUCCI SKV; SANTOS FM. 2011a. Produção de biomassa e teor de óleo essencial em função da idade e época de colheita em plantas de hortelã-japonesa. Acta Scientiarum 33: 327-334.

CHAGAS JH; PINTO JEBP; BERTOLUCCI SKV; SANTOS FM; BOTREL PP; PINTO LBB. 2011b. Produção da hortelã-japonesa em função da adubação orgânica no plantio e em cobertura. Horticultura Brasileira 29: 412-417.

COMISSÃO DE FERTILIDADE DO SOLO DO ESTADO DE MINAS GERAIS. 1999. Recomendações para o uso de corretivos e fertilizantes em Minas Gerais: $5^{a}$ aproximação. Viçosa: CFSEMG, 359p.

CORRÊA RM. 2008. Adubação orgânica, intensidade e qualidade de luz no crescimento de plantas, características anatômicas $e$ composição química do óleo essencial de orégano (Origanum vulgare L.). Lavras: UFLA. $131 \mathrm{p}$ (Tese doutorado).
COSTA LCB; PINTO JEBP; CASTRO EM; ALVES E; BERTOLUCCI SKV; ROSAL LF. 2010. Effects of coloured shade netting on the vegetative development and leaf structure of Ocimum selloi. Bragantia 69: 349-359.

CROTEAU RB; DAVIS EM; RINGER KL; WILDUNG MR. 2005. (-)-Menthol biosynthesis and molecular genetics. Naturwissenschaft 92: 562-77.

FERREIRA DF. 2003. SISVAR - Sistema de análise de variância: versão 4.2. Lavras: UFLA.

JONES RH; MCLEOD KW. 1990. Responses to a range of light environments in Chinese Tallowtree and Carolina Ash seedlings. Forest science 36: 851-862.

KASPERBAUER MJ. 1994. Light and plant development. In: WILKINSON RE. (ed). Plant environment interactions. New York: Marcel Dekker. p. 83-123.

LI S; RAJAPAKSE NC; YOUNG RE; OIR. 2000. Growth responses of chrysanthemum and bell pepper transplants to photoselective plastic films. Scientia Horticulturae 84: 215-225.

LI Y; CRAKER LE; POTTER T. 1996. Effect of light on essential oil production of sage (Salvia officinalis) and thyme (Thymus vulgaris). Acta Horticulturae 426: 419-426.

MARTINS JR; ALVARENGAAA; CASTRO EM; PINTO JEBP; SILVA APO. 2008. Avaliação do crescimento e do teor de óleo essencial em plantas de Ocimum gratissimum L. cultivadas sob malhas coloridas. Revista Brasileira de Plantas Medicinais 10: 102-107.

MATTOS SH; INNECCO R. 2002. Idade ideal de corte da Mentha arvensis L. como produtora de óleo essencial e mentol para o Estado do Ceará, Brasil. Revista Brasileira de Plantas Medicinais 5: 15-18.

MELO AAM; ALVARENGA AA. 2009. Sombreamento de plantas de Catharanthus roseus (L.) G. Don'Pacifica White' por malhas coloridas: desenvolvimento vegetativo. Ciência e Agrotecnologia 33: 514-520.

MING LC. 1998. Adubação orgânica no cultivo de Lippia alba (Mill.) N. E. Br.- verbenaceae. In: MING LC. (coord). Plantas medicinais, aromáticas e condimentares: avanços na pesquisa agronômica. Botucatu: UNESP. 1: 165-191.

NATIONAL INSTITUTE OF STANDARDS
AND TECHNOLOGY. 1998. PC version of the NIST/EPA/NIH Mass Spectral Database. Gaithersburg, MD: U.S. Department of Commerce, (Software de química).

OLIVEIRA MI; CASTRO EM; COSTA LCB; OLIVEIRA C. 2009. Características biométricas, anatômicas e fisiológicas de Artemisia vulgaris L. cultivada sob telas coloridas. Revista Brasileira de Plantas Medicinais 11: 56-62.

OREN-SHAMIR OM; GUSSAKOVSKY EE; SHPIEGEL E; LEVI AN; RATNER K; OVADIA R; SHAHAK Y. 2001. Colored shade nets can improve the yield and quality of green decorative branches of Pittosporum variegatum. Journal Horticultural Science Biotechnology, 76: 336-353.

PONS TL; BERKEL YEM J. 2004. Speciesspecific variation in the importance of the spectral quality gradient in canopies as a signal for photosynthetic resource partitioning. Annals of Botany 94: 725-732.

SALES JF; PINTO JEB; BOTREL PP; SILVA FG; CORREA RM; CARVALHO JG. 2009. Germinação de sementes, crescimento da planta e composição química do óleo essencial de Hyptis marrubioides EP1., Lamiaceae. Bioscience Journal 25: 60-68.

SHAHAK Y; GUSSAKOVSKY EE; GAL E; GAELEVIN R. 2004. Colornets: crop protection and light-quality manipulation in one technology. Acta Horticulturae 659: 143-161.

SOUZA GS; CASTRO EM; SOARESAM; PINTO JEBP; RESENDE MG; BERTOLUCCI SKV. 2011. Crescimento, teor de óleo essencial conteúdo de cumarina de plantas jovens de guaco ( Mikania glomerata Sprengel) cultivadas sob malhas coloridas. Revista Biotemas 24: 1-11.

SOUZA MF. 2007. Influência do sombreamento na produção de fitomassa e óleo essencial em Alecrim-pimenta (Lippia sidoides Cham.). Revista Brasileira de Biociências 5: 108-110.

TAIZ L; ZEIGER E. 2004. Fisiologia vegetal. Porto Alegre: Artmed. 719 p. (3 ed.).

VAN DEN DOOL DH; KRATZ PDJA. 1963. Generalization of the retention index system including linear temperature programmed gas-liquid partition chromatography. Journal of Chromatogrography 11: 463-471. 